\title{
A RARE CASE OF A TRANS-STOMAL HERNIA, COMBINED WITH UNDIAGNOSED MEDIASTINAL LYMPHADENOPATHY IN A PATIENT WITH RECTAL CANCER
}

\section{Kameliya T. Tsvetanova, ${ }^{1}$ Dobromir D. Dimitrov, ${ }^{1}$ Hyuliya E. Feradova, ${ }^{2}$ Vasil Nanev, ${ }^{1}$ Tsvetomir M. Ivanov, ${ }^{2}$ Todor Iv. Dimitrov}

Clinic of Anaesthesiology, Reanimation and Intensive Care, Oncology Center, Medical University - Pleven ${ }^{1}$ Department of Surgical Oncology, Medical University - Pleven ${ }^{2}$ Clinic of Gynecologic Oncology, Department of Minimally-invasive Gynecology Surgery, Medical University - Pleven, Bulgaria

\section{Corresponding Author}

Kameliya T. Tsvetanova

Clinic of Anaesthesiology, Reanimation and Intensive Care,

Oncology Center,

University Hospital - Pleven,

8A, Georgi Kochev, blvd

Pleven, 5800

Bulgaria

e-mail: kamelia_tsvetanova@abv.bg

Received: April 01, 2015

Revision received: April 04, 2015

Accepted: May 18, 2015

\begin{abstract}
Summary
Colon cancer is one of the most common malignant diseases with high grade of malignancy and mortality at high rate. Approximately one million people are diagnosed with colorectal cancer each year. Metastases affect mostly the liver, followed by the lungs. Here is a rare case of a patient with rectal cancer without disease progression or recurrence who underwent surgery due to a trans-stomal hernia, combined with high transstomal fistula of the ileum. Acute respiratory failure developed in the postoperative period and led to fatal deterioration as a result of enlarged metastatic mediastinal lymph nodes, which was very difficult to diagnose.
\end{abstract}

Key words: rectal cancer, transstomal hernia, lymph node metastases

\section{Introduction}

Colorectal cancer is the third most commonly diagnosed cancer (excluding skin cancer) and the second most common cause of cancer death in the US $[1,2]$. Increased life expectancy has led to elevating the mean age of the patients at the time of diagnosis of colon cancer and subsequent treatment. $[3,4]$

Mortality rate in the period of 30 days after surgery for colorectal cancer has been reported by many authors, varying from $2.7 \%$ to $5.7 \%$ [5-16].

Colorectal cancer survival is highly dependent upon the stage of disease at diagnosis. The 5-years survival rate typically ranges from $90 \%$ for cancers detected at the localized stage; about $70 \%$ for cases with regional spread to $10 \%$ for the metastatic disease.

\section{Case report}

We present the case of a 70- year-old male patient, diagnosed with rectal cancer 15 years ago. After diagnosis he underwent an anterior rectal resection. Two years later he was re-operated on because of 
ileus. Transverse colostomy was brought to surface on the left side of the abdomen.

In 2015 the patient was admitted to the Clinic of Surgical Oncology in the Oncology Center of the University Hospital - Pleven, with anal bleeding and unusual secretion of the stoma with skin irritation around it.

Physical examination showed good general condition with no pathological findings. During examination of the stoma, a transstomal hernia, combined with high transstomal fistula of the ileum was found. The surrounding skin was red and painful (Figure 1).

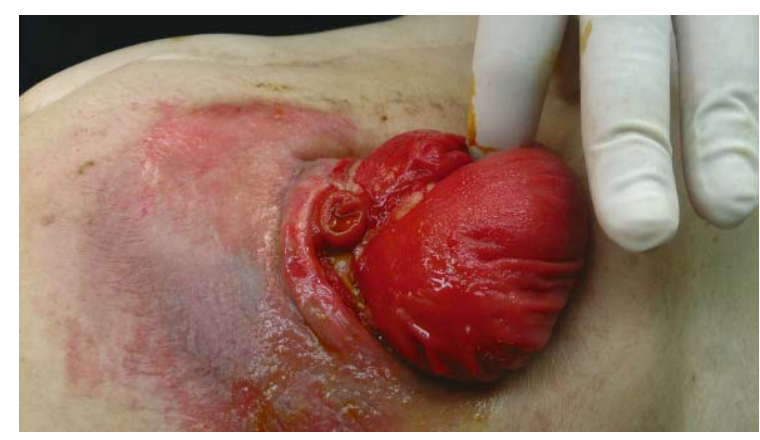

Figure 1. Transverse colostomy with transtomal hernia and fistula of the ileum

Comorbidities such as hypertension, chronic obstructive pulmonary disease and bilateral varicose veins of the lower extremities were registered. Blood analysis revealed moderate hypoxemia: $\mathrm{PaCO} 2-\mathrm{i} 52 \%$, SAT - $85 \%$.

On the chest radiograph, enhanced lung markings and free costophrenic angles were visualized (Figure 2).

The surgery performed included reposition of the transverse colostomy to the right of the abdominal wall, suture of the ileum, parietal abdominoplasty, debridement, lavage and drainage of the abdominal cavity. The operation proceeded smoothly.

Postoperatively, the patient was transferred for recovery to the Intensive Care Unit in the same oncology centre.

The first day after the operation was uneventful. Laboratory results were in the normal range. Respiration and hemodynamics were stable. On the second postoperative day, syndromes of anaemia and hypoproteinemia were noted: haemoglobin $-100 \mathrm{~g} / \mathrm{L}$, total protein $-49 \mathrm{~g} / \mathrm{L}$, albumin $-35 \mathrm{~g} / \mathrm{L}$. The patient suffered from tachycardia $(120 \mathrm{bpm})$ and hypertension $(180 / 100 \mathrm{~mm} \mathrm{Hg})$. Ultrasound examination revealed free fluid in the abdomen. After a

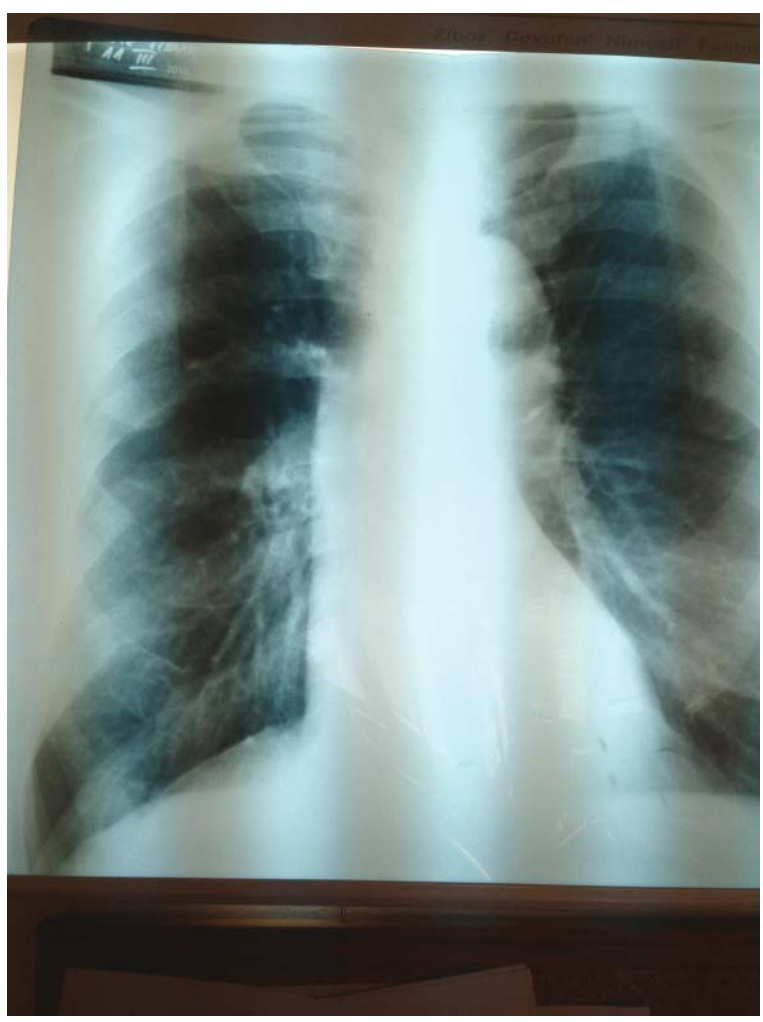

Figure 2. Chest radiograph before surgery without pathological findings

consultation with surgeons and anaesthesiologists, the patient was operated on emergently because of suspected internal bleeding. During surgery, masses of blood clots were found and removed. A small bleeding vessel around the stoma was ligated. After surgery, transfusion of human serum albumin, blood and plasma transfusion, infusion of anticoagulants and antibiotics, indicated by the antibiogram, as well as intravenous fluid resuscitation were performed. The amount of transfused iso-group blood was $1500 \mathrm{ml}$, and that of the plasma -1420 $\mathrm{ml}$. Mucolytic therapy, inhalation and electrical stimulation of the gastrointestinal tract were performed during recovery.

Despite surgery and no evidence of a consequent acute surgical problem, the patient worsened progressively. Acute respiratory failure and fever were added to the syndromes of anaemia and hypoproteinemia.

The new chest radiograph did not show any differences from the first one (Figure 3 ).

The patient complained of worsening shortness of breath. He developed tachypnea: the respiration rate rose to 23 per minute. Despite the oxygen supply through a face mask, his acid-base balance deteriorated. The patient developed 


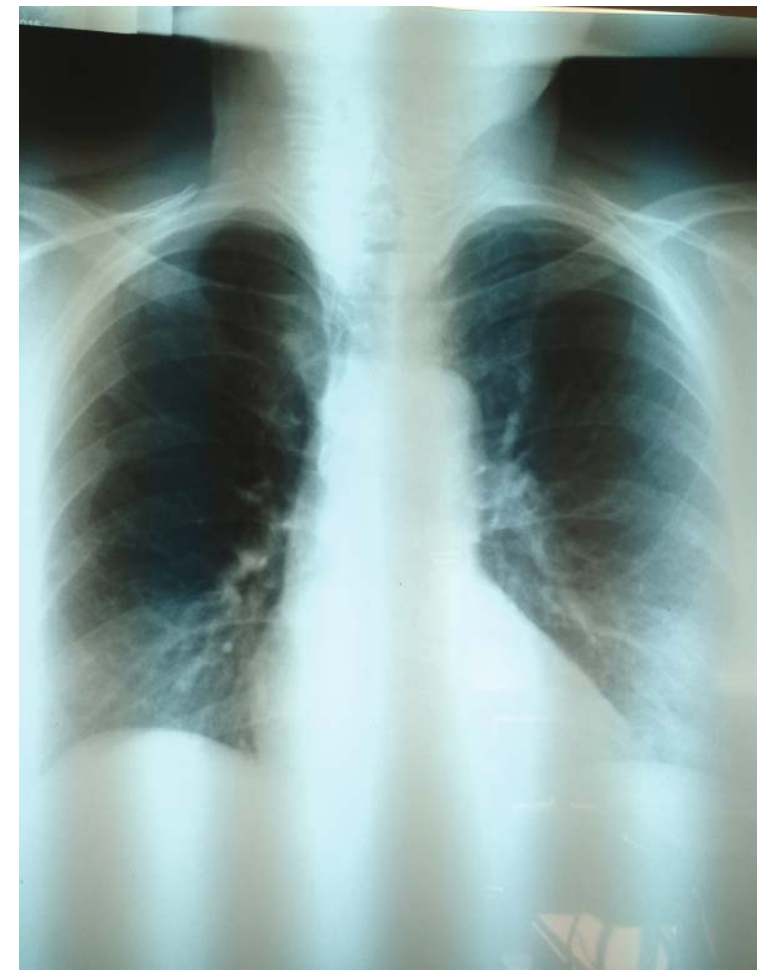

Figure 3. Chest radiograph after two surgeries with no evidence for pathology

severe hypoxia and hypoxemia.

Computer tomography examination reported no dissemination of the underlying disease. CT of the lungs revealed emphysematous parenchyma and extensive consolidations of his bilateral lung fields, bronchiectasis and pleural effusions of approximately $400 \mathrm{ml}-500 \mathrm{ml}$. No pathologically enlarged mediastinal lymph nodes were visualized (Figure 4).

On the seventh postoperative day, the patient became somnolent and difficult to contact. The acid-base balance deteriorated. Fibrobronchoscopy was performed. A minimal amount of purulent secretions was actively aspirated and sent for microbiological examination. During the procedure, bronchial deformation due to right-side pressure was found, without evidence of tracheitis. Finally, enlarged metastatic mediastinal lymph nodes were diagnosed.

On the eighth postoperative day, the patient became somnolent-soporous, with rapid and wheezy breathing. On the ninth day, he went into the state of coma with severe respiratory failure. In spite of the cardio-pulmonary resuscitation performed, the outcome was lethal.

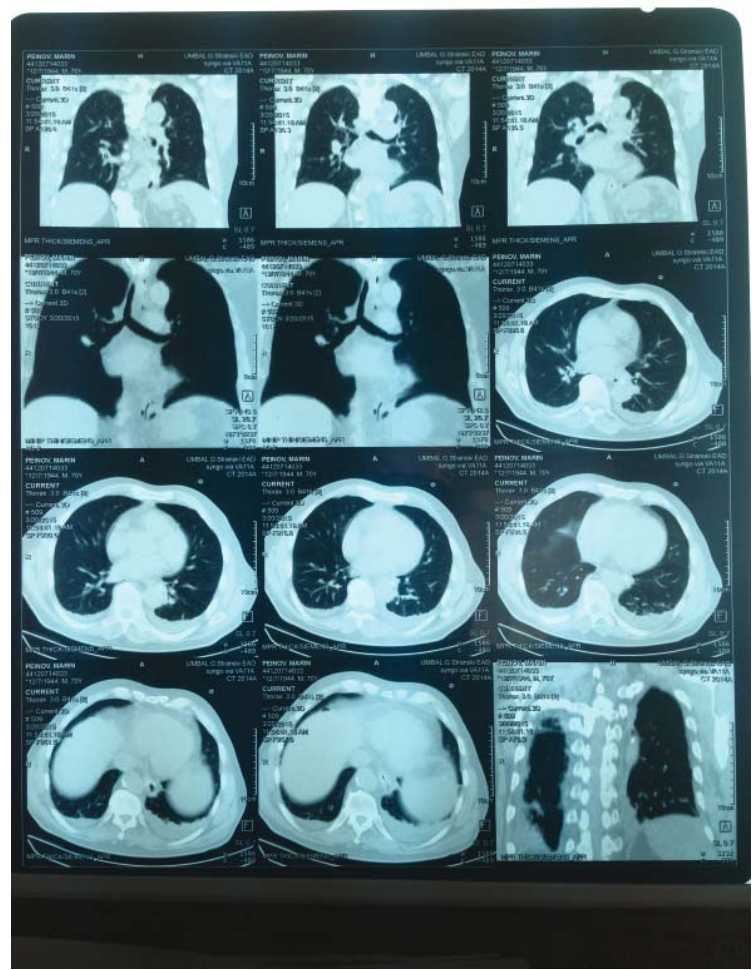

Figure 4. CT of the chest - emphysematous parenchyma, bilateral consolidations, bronchiectasis, pleural effusions. No enlarged mediastinal lymph nodes were visualized.

\section{Discussion}

Colorectal cancer is the third most common cancer among both men and women. It is also the third most common cause of cancer death among men and women separately, and the second most common cause of cancer death in men and women combined. The most common metastatic sites it affects are the liver, bone marrow and lungs $[17,18]$.

In 2014 El Halabi reported a case with moderately differentiated colorectal adenocarcinoma. Computed tomography showed no pathological changes in the liver. Pathologically enlarged mediastinal lymph nodes were not visualized either. It was only by endoscopic ultrasound that an enlarged mediastinal lymph node was detected with a size of $5.2 \times 3.5 \mathrm{~cm}$ [19].

Welter et al. (2007) also studied patients with colorectal cancer, dividing them into three groups according to the localization of metastatic pulmonary lymph nodes. Comparing their survival after surgical removal of the lymph nodes, the authors reported that median survival was 47.2 months after the first metastasectomy. 
Ten patients with intra-pulmonary node location had a median survival of 86 months, 12 patients with hilar localization had a median survival of 24.5 months while those with mediastinal lymph node involvement survived 34.7 months. The difference in survival in intra-pulmonary, hilar and mediastinal localization of metastatic lymph nodes was statistically significant $(\mathrm{p}=0.008)$. The five-year survival rate in lung, hilar and mediastinal location was $78.5 \%, 0 \%$ and $0 \%$, respectively. Perioperative mortality was $0 \%$. This team of authors concluded that surgical removal of enlarged metastatic lymph node is imperative because of the close connection between their presence and increased mortality in these patients [20].

Similar results were reported by Kim et al. (2010). According to them, $10 \%$ to $15 \%$ of all the patients who undergo surgical treatment of colorectal cancer develop lung metastases. They proved that the average interval between colorectal resection and lung metastases was $24.0 \pm 15.1$ months. Overall survival was 3 to 5 years. The authors came to the conclusion that surgical removal of metastatic lymph nodes increased survival [21]. Horner et al. have also reported low survival rates in patients with colorectal cancer with mediastinal lymph node metastases: $20 \%$ of metastatic nodes are not detectable preoperatively [22].

\section{Conclusions}

Colorectal cancer is a malignant disease, often with lethal outcome because of severe complications. Metastases in the lungs are common. However, the enlarged metastatic mediastinal lymph nodes are difficult to diagnose. This is a prerequisite for the development of severe respiratory failure that often leads to death.

\section{References}

1. Biondi A, Grosso G, Mistretta S, Toscano C, Gruttadauria S, Basile F. Laparoscopic-assisted versus open surgery for colorectal cancer: shortand long term outcomes comparison. J Laparoendosc Adv Surg Tech A. 2013;23(1):1-7.

2. Biondi A, Tropea A, Basile F: Clinical rescue evaluation in laparoscopic surgery for hepatic metastases by colorectal carcer. Surg Laparosc Endosc Percutan Tech. 2010;20(2):69-72.
3. Sun J, Jiang T, Qui Z, Cen G, Cao J, Huang K, er al. Short-term and medium-term clinical outcomes of laparoscopic-assisted and open surgery for colorectal cancer: a single center retrospective case-control study. BMS Gastroenterol. 2011;11:85.

4. The Clinical Outcomes of Surgical Therapy Study Group. A comparison of laparoscopically assisted andopen colectomy for colon cancer. N Engl J Med 2004;350(20):2050-9.

5. Davila JA, Rabeneck L, Berger DH, El-Serag HB. Postoperative 30-day mortality following surgical resection for colorectal cancer in veterans: changes in the right direction. Dig Dis Sci. 2005;50(9):1722-8.

6. Nickelsen TN, Jorgensen T, Kronborg O. Thirtyday mortality after surgery for colorectal cancer in Denmark. Colorectal Dis. 2005;7(5):500-6.

7. Nickelsen TN, Jorgensen T, Kronborg O. Lifestyle and 30-day complications to surgery for colorectal cancer. Acta Oncol. 2005;44(3):218-23.

8. Glen P, Simpson MF, Donnelly L, Leonard S, Macdonald A. Thirty-day mortality from colorectal cancer surgery within a deprived population. Colorectal Dis. 2005;7:193-5.

9. Fazio VW, Tekkis PP, Remzi F, Lavery IC. Assessment of operative risk in colorectal cancer surgery: the Cleveland Clinic Foundation colorectal cancer model. Dis Colon Rectum. 2004;47(12):2015-24.

10. Rabeneck L, Davila JA, Thompson M, El-Serag HB. Outcomes in elderly patients following surgery for colorectal cancer in the veterans affairs health care system. Aliment Pharmacol Ther. 2004;20(10):1115-24.

11. Urbach DR, Baxter NN. Does it matter what a hospital is "high volume" for? Specificity of hospital volume-outcome associations for surgical procedures: analysis of administrative data. Qual SafHealth Care. 2004;13(5):379-83.

12. Menon KV, Farouk R. An analysis of the accuracy of P-POSSUM scoring for mortality risk assessment after surgery for colorectal cancer. Colorectal Dis. 2002;4(3): 197-200.

13. Ascanelli S, Navarra G, Tonini G, Feo C, Zerbinati A, Pozza E, Carcoforo P. Early and late outcome after surgery for colorectal cancer: elective versus emergency surgery. Tumori. 2003;89(1):36-41.

14. Damhuis RA, Wereldsma JC, Wiggers T. The influence of age on resection rates and postoperative mortality in 6457 patients with colorectal cancer. Int $\mathrm{J}$ Colorectal Dis. 1996;11(1):45-8.

15. Agarwal N, Leighton L, Mandile MA, Cayten CG. Outcomes of surgery for colorectal cancer in patients age 80 years and older. Am J Gastroenterol. 1990;85(9):1096-101.

16. Tekkis PP, Poloniecki JD, Thompson MR, Stamatakis JD. Operative mortality in colorectal cancer: prospective national study. BMJ 
2003;327(7425):1196-201.

17. Jemal A, Clegg LX, Ward E, Ries LA, Wu X, Jamison PM, et al. Annual report to the nation on the status of cancer, 1975-2001, with a special feature regarding survival. Cancer. 2004;101(1):327

18. Ries L AG,Melbert D, Krapcho M, Mariotto A, Miller BA, Feuer EJ, et al. SEERS cancer statistics review, 1975-2004 [Internet]. Bethesda (MD): National Cancer Institute; [cited 2015 March 14]. Available from:

http://seer.cancer.gov/archive/csr/1975_2005/

19. El Halabi MM, Chaaban SA, Meouchy J, Page S, Saleyers WJ Jr. Colon cancer metastasis to mediastinal lymph nodes without liver or lung involvement: A case report. Oncol Lett. 2014;8(5):2221-4.
20. Welter S, Jacobs J, Krbek T, Stamatis G. Longterm survival after repeated resection of pulmonary metastases from colorectal cancer. Ann Thorac Surg. 2007;84(1):203-10.

21. Kim HJ, Key BH, Lee SC, Lee YS, Kang WK, Cho $\mathrm{HM}$, et al. Surgical resection from colorectal cancer. J Korean Soc Coloproctol. 2010;26(5):358-8.

22. Horner M. Ries L, Krapcho M, Neyman N, Aminou R, Howlader N, et al. SEER Cancer Statistics Review, 1975-2006 [Internet]. Bethesda (MD): National Cancer Institute; [cited 2015 March 14]. Available from: . http://seer.cancer.gov/archive/csr/1975_2006/ 